\title{
Dilemma of Green Logistics in China
}

\author{
Lan Lan ${ }^{1,2}$, Wu Chunyou ${ }^{1}$, Ding Feng ${ }^{1, *}$, Zhao $\mathrm{Xu}^{1}$ and Guo Jianfeng ${ }^{3}$ \\ ${ }^{1}$ Dalian University of Technology, Dalian, Liaoning, 116600, China; ${ }^{2}$ Shenyang University, Shenyang, Liaoning, \\ 110000, China; ${ }^{3}$ Information Security and Software Testing Center, Shenyang, Liaoning, 110000,China
}

\begin{abstract}
The purpose of this paper is to introduce the development dilemma of green logistics in China in the relationship betweent the public, company and government. The paper particularly discussed the cost, energy consumption, competitiveness, resource disposition, circulation mode, and application of new technology in China logistics. A evaluation model of green logistics growth capacity is given. And finally comes up with strategies aiming to solve the problems fa-
\end{abstract} ced in China.

Keywords: China green logistics, development dilemma, strategies of development.

\section{INTRODUCTION}

Definitions for Green Logistics to be found various in the previous works $[7,15]$. And described kinds of attempts to measure and minimize the ecological impact caused by logistics activities. This includes all activities of the forward and reverse flows of products, information and services between production point and consumption point. It is a concept to characterize logistics systems and approaches to minimize environmental damage during operations with advanced technology and equipment. [7] Previous study has contributed to reduce the greenhouse gas emissions, noise and accidents, and developed a sustainable balance between economic, environmental and social objectives. [9, 14]

For China, green logistics is not only profits concerned with people, companies and governments but with the environmental sustainability of the whole society. Unfortunately, it is often neglected by most people due to its intangibility and high cost. Green logistics is the transformation and upgrading of traditional logistics. The cost of logistics has become a tight constrain in connection with manufacturing and consumption [10-13].

A previous survey [8] shows that the vast majority of companies want to reduce the harmful activities in logistics, but feel constrained by business climate. Most companies have undertaken some work driven by legislation and the desire to reduce costs. This is much more similar to China mainland today. For the companies, the commercial benefit of responding to many environmental concerns is full of considerable uncertainty. Therefore a large proportion of companies in China prefer to wait until forced into action by legislation.

\section{PROBLEMS OF DEVELOPING GREEN LOGIS- TICS}

With the rapid development of modern logistics industry, the social market is increasing comprehensively and

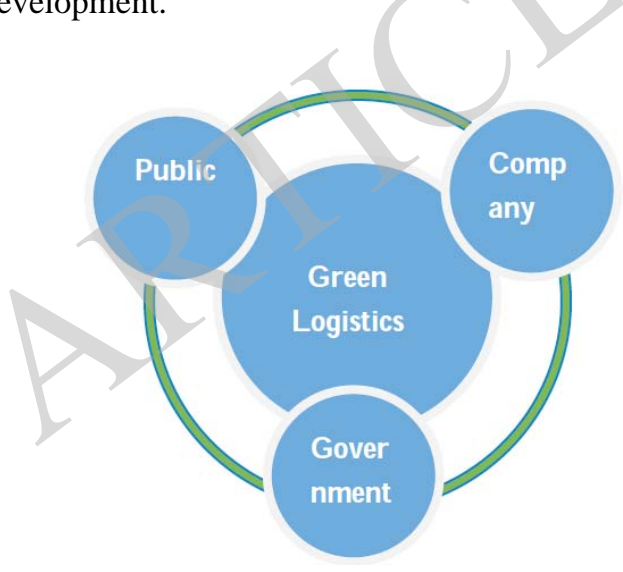

Fig. (1). Profits chain linked by green logistics.

promoting green logistics as well as the basic economic environment is all gradually improving. However, there is still quite a long way to get rid of the restriction caused by traditional logistics economy. Theoretically, though the green logistics is guided by the government, promoted by the market, forced by the environment and demanded by the society, there are quite a number of obstacles in practice relevant to every domain, every industry, every level and every circle. As Fig. (1) shows, green logistics bind the profits of public, company and government with a circle. Problems mainly faced in developing green logistics are as follows.

\subsection{High Cost of Logistics Industry}

Green logistics serves as an important link for sustainable economic development. In China's economic operation, the total cost of social logistics still occupies a high rate in GDP as high as $18 \%$ [16], which is about $6.8 \%$ higher than the world average level and more than 1 time higher than the developed countries such as America, Japan and Germany. When compared with BRICS countries, this rate is still about 5\%-7\% higher than India and Brazil. The high cost of logistics is a big obstacle for the development of green logistics.

\subsection{High Energy Consumption}

According to the statistics [1], in 2012, China's primary energy consumption is about 3.62 billion tons of coal, $20 \%$ 


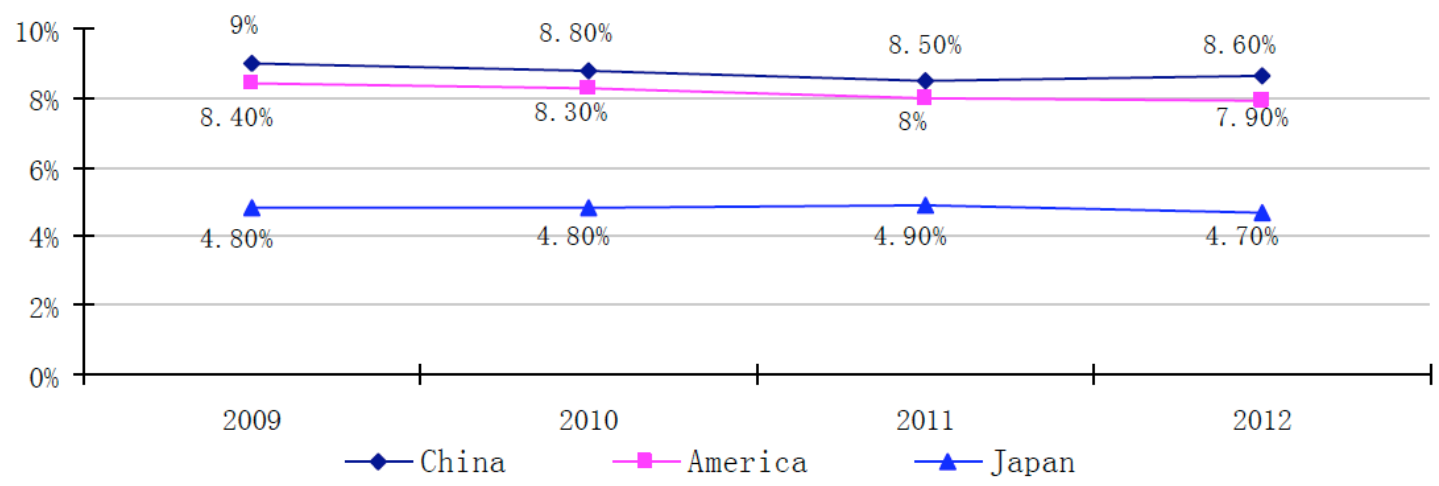

Fig. (2). Comparison of logistics expense ratio of enterprises spend on sales.

of world's energy. The energy intensity is about 2.5 times higher than the average level of the world, what's more, this rate is 3.3 times higher than America, 7 times than Japan and also higher than some developing countries such as Brazil and Mexico. Every consumption of standard coal in China will bring GDP 25000 Yuan, for America, it will create GDP 31000 Yuan, and for Japan, it's 50000 Yuan. High energy consumption is lagging the pace of developing green logistics in China.

\subsection{Lack of International Competitiveness}

Data [17] from Ministry of Commerce People's Republic of China shows that in 2013 China's total volume of foreign trade reached 539.64 billion dollars, which is only about a half of the volume of America. View from the added value of foreign trade, the developing country is usually about $30 \%$, and the developed country is about 50\% and the innovative countries headed by America is as high as $70 \%$, but China is less than $30 \%$ [2]. The future increase of foreign trade would be dark if the trade is only supported by consumption of energy and other products with low added value instead of improving the competitiveness and the added value of products.

\subsection{Unreasonable Logistics Resources Disposition}

Unreasonable disposition of logistics resources caused low efficiency and grievous waste. According to the calculations, after the out-put of the grain, the total amount of the wasted grain has reached 35 billion $\mathrm{Kg}$ per year, which is $5.8 \%$ of a whole year' s grain out-put [3], during the links of farmers' storage, transportation and machining. This kind of waste has been one of the key factors that threaten the grain security. According to the analysis [4], the unloaded ratio in China is as high as over $40 \%$. It takes a seriously negative influence on the environment, energy consumption. Furthermore, small scale, dispersal disposition, disordered situation and unqualified products are all prominent problems.

\subsection{Low Efficient Circulation Mode}

Low efficient circulation mode is showed mainly in two aspects. Firstly, the process of the construction of modern circulation system based on supplying chain is relatively slow. The social logistics resources are lack of efficient integration and can't be used intensively, which have caused the low efficiency and high prices of logistics. In 2012, accord- ing to the investigation of key enterprises investigated by China Logistics Information Center, Chinese enterprises' external logistics expense is about $61.6 \%$ of the enterprise's total logistics expense, which is $9 \%$ lower than Japanese enterprises, and this gap is quite evident. Secondly, the construction of logistics resources integration falls behind relatively. The social resources are slowly circulated with too many intermediate links. This is the main reason caused high price of logistics. For example, the ratio of the corporation of sea and railway transportation is far below the average level of the world, and at present, the ratio of corporation of sea and railway transportation of port-container is internationally about $20 \%$. America is $40 \%$, while China is only about $2.6 \%$. The times of the turnover of industrial current assets are less than 3, which is far lower than that of Japan and Germany: 9-10 times [5]. The proportion of logistics costs to sales in various industries is another important indicator reflecting the level of logistics costs. According to the survey [18] of key enterprises by China Logistics Information Center (See Fig. 2) in 2012, China's industrial, wholesale and retail business logistics costs as a percentage of sales is $8.6 \%, 3.9 \%$ higher than Japanese companies, $0.7 \%$ higher than the U.S. companies. Among them, the industrial enterprises were $9.2 \%$, wholesale and retail businesses is $7.8 \%$.

\subsection{Lack of Application of New Technology}

Though the business scale of logistics is large, the profit of the companies is low. This is mainly because the high cost of operation. The investment for upgrading the equipment or rebuild the business process with new technology is a heavy burden for a company with low profit. Many modern technologies used by logistics companies out of China widely, such as barcode, RFID, EDI, GPS and so on, have been accepted by China logistics companies. But the pace of using new technology is slower than their competitors'. This has restricted the improving of logistics efficiency. It is just a start. There will be a reshuffle in logistics companies in the next decade and the ones with low efficiency will be eliminated.

\section{MEASURES FOR SOLVING THE PROBLEMS}

Data [19] from National Bureau of Statistics of the People's Republic of China shows that the increasing of total freight traffic nearly stopped from 2012 to 2013 and the freight traffic even slide down at the same time. See Fig. (3). 


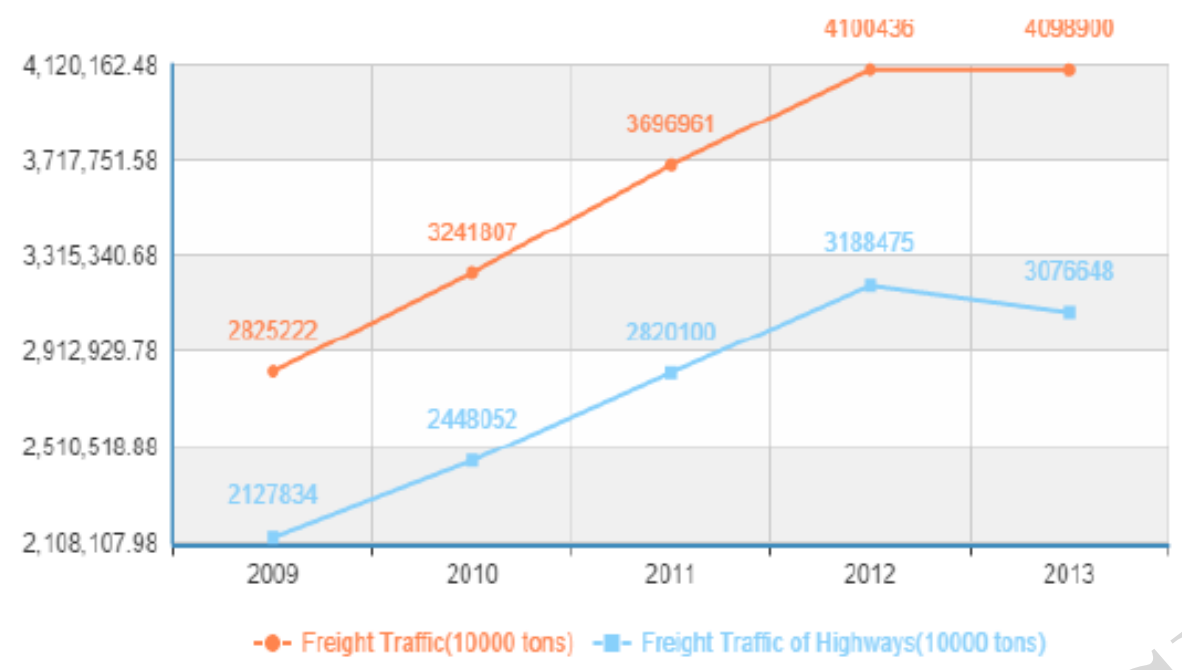

Fig. (3). Total freight traffic and freight traffic of highways.

There is no total or perfect plan to keep China logistics increasing sustainable. But we can make some improvement to get the logistics industry competitive.

\subsection{Setup Mechanism for Green Logistics}

Top level design for green logistics as a country strategy is very necessary. International trade has become a most important part of China economy, and we can get more profit by green logistics. A new working plan for the coordinated development of environment, economy and society should be designed. The relationship between public, company and government in the circulation of green logistics should be rethought. Especially the mechanism design and run by government for logistics should be changed. The highway charge is an example. The charge is too high for logistics companies, and the only way for companies to get profits is to overload each cargoes. This causes series problems, such as road damages, traffic accidents, more emissions, and so on. Making the charge public is an effective way to change the situation. Government should provide more public services and the service price should be determined by the market. If so, the cost of the logistics companies will be cut down. A long-term development mechanism will help green logistics in China make a new progress.

\subsection{Establish Green Growth Evaluation Model}

For describing the green growth capability of logistics of an area, the authors designed a green growth evaluation model to calculate the value of green logistics growth capability. Variables show as Table $\mathbf{1}$.

Green logistics growth capability:

$$
T=B_{1}+B_{2}
$$

Basic capability:

$$
B_{1}=\sum_{i=1}^{4} C_{i}
$$

Green capability

$$
B_{2}=\sum_{i=5}^{8} C_{i}
$$

Industry environment:

$$
C_{1}:\left\{x_{1}, x_{2}, x_{3}, x_{4}\right\}
$$

Education environment:

$C_{2}:\left\{x_{5}, x_{6}, x_{7}\right\}$

Logistics capability:

$C_{3}:\left\{x_{8}, x_{9}, x_{10}, x_{11}, x_{12}\right\}$

Negative index:

$C_{4}:\left\{x_{13}, x_{14}, x_{15}\right\}$

Per capita index:

$C_{5}:\left\{x_{16}, x_{17}, x_{18}, x_{19}\right\}$

Unit accident index:

$C_{6}:\left\{x_{20}, x_{21}\right\}$

Unit emission index:

$C_{7}:\left\{x_{22}, x_{23}\right\}$

Unit inputloutput index:

$C_{8}:\left\{x_{24}, x_{25}, x_{26}\right\}$

which,

$x_{16}=x_{8} / x_{1}, x_{17}=x_{10} / x_{1}$,
$x_{18}=x_{12} / x_{1}, x_{19}=v_{0} / x_{1}$,
$x_{20}=x_{10} / x_{13}, x_{21}=v_{0} / x_{13}$,
$x_{22}=x_{10} / x_{15}, x_{23}=v_{0} / x_{15}$,
$x_{24}=v_{0} / x_{3}, x_{25}=v_{0} / x_{4}$,
$x_{26}=v_{0} / x_{7}$,

$v_{0}$ is added value of logistic industry.

From (1) (2) and (3) we can get,

$T=B_{1}+B_{2}=\sum_{i=1}^{4} C_{i}+\sum_{i=5}^{8} C_{i}=\sum_{i=1}^{8} C_{i}$

Suppose we try to calculate the green logistics capability of $n(n>1)$ years, the green logistics capability of year $\mathrm{j}\left(\mathrm{j} \in\left[\begin{array}{ll}1, & \mathrm{n}\end{array}\right]\right)$ is denoted by $T_{j}$, and statistical value of index 
Table 1. Calculation variables for green logistics growth capability.

\begin{tabular}{|c|c|c|}
\hline Index Name & Var & Unit \\
\hline Urban Employed Persons & $x_{1}$ & 10000 persons \\
\hline Average Wage of Employed Persons in Urban Units & $x_{s}$ & yuan \\
\hline Total Investment in Fixed Assets in the Whole Country & $x_{*}$ & 100 million yuan \\
\hline Local Governments Expenditure, Transportation & $x$ & 100 million yuan \\
\hline Number of Higher Education Schools & $x_{s}$ & -- \\
\hline $\begin{array}{l}\text { Number of New Students Enrollment of Regular } \\
\text { Institutions of Higher Education }\end{array}$ & $x_{\mathrm{s}}$ & 10000 persons \\
\hline Educational Funds & $x_{r}$ & 10000 yuan \\
\hline Passenger Traffic & $x_{s}$ & \\
\hline Passenger-Kilometers & $x$ & 100 million passenger-km \\
\hline Freight Traffic & $x_{1: 4}$ & 10000 tons \\
\hline Freight Ton-Kilometers & $x_{1}$ & 100 million ton-km \\
\hline Pieces of Express Mail Services & $x_{1}$ & $10000 \mathrm{pcs}$ \\
\hline Number of Traffic Accidents, Total & $x_{1 \times}$ & time \\
\hline Direct Property Losses on Traffic Accidents, Total & $x_{1}$ & 10000 yuan \\
\hline Sulphur Dioxide Emission in Waste Gas & $x_{1}$ & ton \\
\hline Passenger Traffic/ Urban Employed Persons & $x_{1+1}$ & -- \\
\hline Freight Traffic/ Urban Employed Persons & $x_{1 \gamma}$ & ton/person \\
\hline Pieces of Express Mail Services/ Urban Employed Persons & $x_{1 x}$ & pieces/person \\
\hline Added value of logistic industry /Urban Employed Persons & $x_{14}$ & 10000 yuan/person \\
\hline Freight Traffic/ Number of Traffic Accidents, Total & $x_{s}$ & 10000 ton/accident \\
\hline Added value of logistic industry / Number of Traffic Accidents, Total & $x_{s 1}$ & 10000 yuan/accident \\
\hline Freight Traffic/ Sulphur Dioxide Emission in Waste Gas & $x_{s:}$ & -- \\
\hline Added value of logistic industry / Sulphur Dioxide Emission in Waste Gas & $x_{S a}$ & 10000 yuan/ton \\
\hline Added value of logistic industry / Total Investment in Fixed Assets in the Whole Country & $x_{x}$ & -- \\
\hline Added value of logistic industry / Local Governments Expenditure, Transportation & $x_{s,}$ & -- \\
\hline Added value of logistic industry / Educatic & $x_{s,}$ & -- \\
\hline
\end{tabular}

$x_{i}$ in year $\mathrm{j}$ is denoted by $x_{i j} . k_{i j}$ stands for the result of normalization process of $x_{i j}$, then we can get:

$k_{i j}=\frac{x_{i j}}{\sum_{j=1}^{n} x_{i j}}$

For easy calculation of green logistics growth capability, let $k_{i 1}$ be a base, and denoted the value of the year $(n-1)$ by $p_{i j}$, then we get,

$p_{i j}=\frac{k_{i j}}{k_{i 1}}=\frac{x_{i j}}{k_{i 1} \cdot \sum_{j=1}^{n} x_{i j}}$

Let:

$\sum_{i=1}^{8} C_{i}=\sum_{i=1}^{26} p_{i j}$
Finding (12), we can get:

$T_{j}=\sum_{i=1}^{26} \frac{x_{i j}}{x_{i 1}}$

This is the evaluation value of green logistics growth capability.

\subsection{Optimize the Logistics Resources Disposition}

High costs and low reliability are the biggest problems with China's logistics industry. When we plan to upgrade the logistics from traditional to green, it is not enough to focus on the quantity but also the quality. Before arming the business process with advanced technology, the workflow and management process need to be improved. Cargoes, planes, even satellites used by UPS connect a large network with information sharing and tracking. Only with the support of 
accurate business process management, the logistics resources could be scheduled efficient with low cost. So there are two ways to optimize the logistics resources disposition. The first is to invest in hi-tech equipment, and the second is to optimize the business process management. It seems the latter is more important. When the business process management improved, the logistics companies can get more returns from the hi-tech equipment invested and the public(customers) will get more valuable services.

\subsection{Talent Accumulation}

To accelerate the green logistics, talent accumulation is necessary. The history of logistics of America and Japan shows that the improvement of logistics was accumulated by the talents from all area, such as business, management, energy, environment, IT, financial. On the one hand, the education of vocational school should face the requirement of logistics companies, even the whole logistics area. When the students get to work, they will get the job well done easily. After years of practice, their contribution will be great. On the other hand, the policy for talent working in China should be more attractive. Government and companies should take different responsibility for encouraging. The more talents we have, the better logistics we get.

\section{CONFLICT OF INTEREST}

The authors confirm that this article content has no conflicts of interest.

\section{ACKNOWLEDGMENT}

This work is supported by Projects of International Cooperation and Exchanges NSFC (No. 71320107006).

\section{REFERENCES}

[1] X. Wang, "Unit GDP energy consumption up to 2.5 times the world average and academician proposal to develop nuclear power," Xinhua News Agency- Economic Information, 2013.

[2] G. Li, "How to treat "top of trade in goods of China", People's Daily, 2014

[3] H. Du, "700 billion kilograms of grain circulation of waste per year," People's Daily, 2014.

[4] G. Xu, and K. Wang, "Construction of road logistics network operating system," People's Daily, vol. 8, 2014.
[5]

Q. Zeng, "2013 Logistics Operation and 2014 Future Analysis," 2014.

[6] M. Song, S, Wang, Z, Jiang, J. Yang, and Y, Wang, "Will green logistics be promoted by changing industrial structure? A quantitative analysis from 1978 to 2007 in China", Supply Chain Management: An International Journal, vol. 17, no. 1, pp. 5-14, 2012.

[7] M. Thiell, J. Zuluaga, J. Montanez, and B. van Hoof, "Green Logistics - Global Practices and their Implementation in Emerging Markets," pp. 2, 2011.

[8] S. Jan, "Going Green: The Logistics Dilemma", Logistics Information Management, vol. 6, no. 3. pp. $36-43,1993$.

[9] R. Dekker, J. Bloemhof, and I. Mallidis, ”Operations Research for green logistics - An overview of aspects, issues, contributions and challenges," European Journal of Operational Research , vol. 219, pp. 671-679, 2012.

[10] N. Subramanian, M. D. Abdulrahman, X. Zhou, "Integration of logistics and cloud computing service providers: Cost and green benefits in the Chinese context," Transportation Research Part E: Logistics and Transportation Review, vol. 70, pp. 86-98, 2014.

[11] H. S. Cho, "Determinants and Effects of Logistics Costs in Container Ports: The Transaction Cost Economics Perspective," The Asian Journal of Shipping and Logistics, vol. 30, no. 2, pp. 193215, 2014.

[12] K. Hayashi, and T. Nemoto, "Procurement Logistics of Japanese Auto Manufacturers in Inland China - Intermodal Transport Utilizing the Yangtze River," The Asian Journal of Shipping and Logistics, vol. 26, no. 1, pp. 119-137, 2010.

[13] H. Pan, R. Wang, H. Dong, and F. Zhou, "The Research of Logistics Cost and Influencing Factors Based on Cross Docking," Procedia - Social and Behavioral Sciences, vol. 96, no.6, pp. 1812$1817,2013$.

[14] I. Mallidis, and D. Vlachos, "Eleftherios Iakovou, Rommert Dekker.Design and planning for green global supply chains under periodic review replenishment policies," Transportation Research Part E: Logistics and Transportation Review, vol. 72, pp. 210-235, 2014.

[15] GREEN LOGISTICS, What is Green Logistics?, accessed http://www.greenlogistics.org, 2015.

[16] China Purchasing Development Report, China Federation of Logis tics \& Purchasing ,2014.

[17] Ministry of Commerce People's Republic of China, accessed, 2015 ,

http://www.mofcom.gov.cn/article/ae/ai/201402/20140200485297. shtml, in Chinese.

[18] Q. Zeng, "Analysis on 2013 Logistics Opeartion and Prospect for 2014.

Accessed,"

http://www.chinawuliu.com.cn/lhhkx/201403/07/284816.shtml, in Chinese, 2015.

[19] National Bureau of Statistics of the People's Republic of China, Annual Data, accessed, http://data.stats.gov.cn/english/easyquery.htm?cn=C0, 2015.

[20] Global Supply Chain Council,State of Logistics China Survey 2012, 